\title{
Control for Wind Energy Conversion System based on DFIG by Sliding Mode
}

\author{
Lafi Alnufaie* \\ Department of Electrical Engineering, College of Engineering, Shaqra University, Dawadmi, \\ Kingdom of Saudi Arabia; lalnufaie@su.edu.sa
}

\begin{abstract}
Objective: This study focuses on the sliding mode control for active and reactive powers for a WECS based on DFIG. Method: This context used a back-to-back link between the DGIG rotor and the grid then, isolated by the DC transport. Two pieces are considered. The primary one is named the rotor side converter and the second one is the grid side converter, for the two pieces, utilized the flux orientation transformation to contrive the control equation. After that, I synthesized the sliding mode control laws. Finding: Two cases led to designed control that permits us to get the advantages of the sliding mode control and to eradicate its drawbacks. Application: These researches are presented to show the strength of the proposed control law.
\end{abstract}

Keywords: DFIG, Rotor Side Converter Control, Sliding Mode Control, WEC, Wind Energy, Wind Turbine

\section{Introduction}

As alternative energy source, wind turbines have been pulled in wide consideration due to their a few focal points. The generators that are utilized to change over the mechanical control gotten from the wind turbine into electric energy are by and large either Doublyfed Acceptance Generators (DFIG) or Squirrel Cage Induction Generators (SCIG) or Permanent Magnet Synchronous Generators (PMSG). DFIG-based wind energy transformation frameworks (WEC) have the preferences of high energy capture capability, less acoustic clamor, high responsive control bolster execution and lower control rating than back-to-back control converters $\stackrel{1,2}{ }$. Moreover, decoupling of the active and reactive power control responses leads to a better grid integration ${ }^{3}$. There are numerous diverse control plans of DFIG, for the most part based on vector control concept considering stator flux or voltage introduction guideline related with PI, back-to-back controllers. In any case, utilizing straight controller for stator dynamic and receptive powers control does not the proficient strategy to get great comes about due to the nonlinearity of the framework and operational conditions changing. In this attempt, we propose to adjusted sliding mode control to upgrade the vigor of the WEC framework and to accomplish the control goals.

\section{Sliding Mode Control}

Sliding mode control is interesting in its capacity to attain precise, vigorous, decoupled following for a class of nonlinear time-varying frameworks within the nearness of unsettling influences and parameter varietie ${ }^{4}$. The following of the required direction is accomplished through two stages: An approach stage, where the framework is controlled to achieve a predefined sliding 
surface and a sliding stage along the sliding surface. In any case, in arrange to bargain with the nearness of modeling imprecision and of disturbances, the control law should be spasmodic over the sliding surface. Since the execution of the related control exchanging is fundamentally defective, this leads to chattering which includes high control movement and may energize high-frequency elements and can, in this manner, harm the plant ${ }^{5}$. To solve this problem, many solutions have been proposed in the literature ${ }^{6,7} . \operatorname{In}^{5}$, a boundary-layer in the nearness of the sliding surface has been defined to obtain a continuous behavior of the control signal across this surface. Based on the same thought, a fluffy framework has been utilized to characterize this boundary layer and to misuse the human information ${ }^{6}$. To expel the brokenness within the control signal, a few approaches combining sliding mode control and classical controller employing a fluffy administrator can be cited $\stackrel{8}{\text {. }}$

These strategies resolve the issue related to the chattering wonder. In any case, to plan the exchanging signal guaranteeing the drawing closer stage, the upper bounds of both the outside unsettling influences and the basic instabilities must be well known. To overcome these issues, the creators have proposed a guess of the exchanging signal by an versatile fluffy framework to dispose of the chattering wonder without requiring any specific information almost the upper bounds of both estimation blunders and outside unsettling influences ${ }^{6,9}$. Be that as it may, the worldwide soundness of the closed circle framework in these approaches is ensured as it were for a great guess level or for a specific choice of the initial values of the adjustable parameters. In this work we are going show an elective to these approaches ${ }^{10}$.

Firstly; consider a second order nonlinear system with control input:

$$
\ddot{x}=f(x, \dot{x})+g(x, \dot{x}) u
$$

Where $\mathrm{x}$ and $\mathrm{u}$ are state and control vector, separately; $\mathrm{f}$ and $\mathrm{g}$ are both bounded nonlinear capacities of $\mathrm{x}, \mathrm{x}$. The exchanging work is characterized as.

$$
S=\dot{e}+\lambda,
$$

Where $\lambda$ is a positive real scalar. represents the tracking error and is the reference trajectory. We can define the reaching conditionas follows:

$$
S \dot{S}<0
$$

This condition permits to ensure that the framework comes to continuously the surface $S$, that the following blunder $\left(\mathrm{e}, \mathrm{e}^{\mathrm{e}}\right)$ is able to slide to the harmony point $(0,0)$. To fulfill the condition (3), ready to select $S{ }^{\circ}$ as follows:

$$
\dot{S}=-k \operatorname{sign}(S)
$$

Where $\mathrm{k}$ is a positive real sign(S)scalar, is the sign of the function $S$.

When the system attains the sliding surface $S$, it must remain on: $S=0$. So, the global control law leading the reaching the sliding surface and remains on to attain the equilibrium point $(0,0)$, can be chosen as:

$$
u=g^{-1}\left(\ddot{x}_{r e f}-f-\lambda \dot{e}-k \operatorname{sign}(S)\right)=u_{0}+u_{s},
$$

Where:

$$
\begin{gathered}
u_{0}=g^{-1}\left(\ddot{x}_{r e f}-f-\lambda \dot{e}\right), \\
u_{s}=-g^{-1} k \operatorname{sign}(S),
\end{gathered}
$$

Since the signum work, utilized in condition (6), is spasmodic, it is utilizing leads to chattering wonder which can harm the controlled framework Figure 1. A few works within the writing propose to substitute the signum by smooth immersion Figure 2. In any case, we fall apart the following exhibitions and we get vital sales amid the transitory time due to the choice of the boundary layer thickness. Other arrangements like hyperbolic digression have been created but the common major disadvantage related the parameters choice remains. Some creators proposed to utilize fluffy rationale to characterize the boundary layer.

In this case, the performances are upgraded but finding a trade-off between following exhibitions and introductory values of the control signal cannot be proficiently dispensed with. In a few works, creators chosen to expel the drawing closer stage by altering the sliding surface expression such that the framework will be of the sliding surface at $t=0$. In any case, the proposed structure cannot guarantee the vigor of the closed framework within the case of huge unsettling influences. Solving these problems, we propose to choose as follows:

$$
u_{s}=-\frac{S}{\rho^{2}},
$$

Where is a positive scalar. 
This structure is propelled from $\mathrm{H} \infty$ procedure which permits to constrict the impacts of outside unsettling influences without expansive values of control signal.

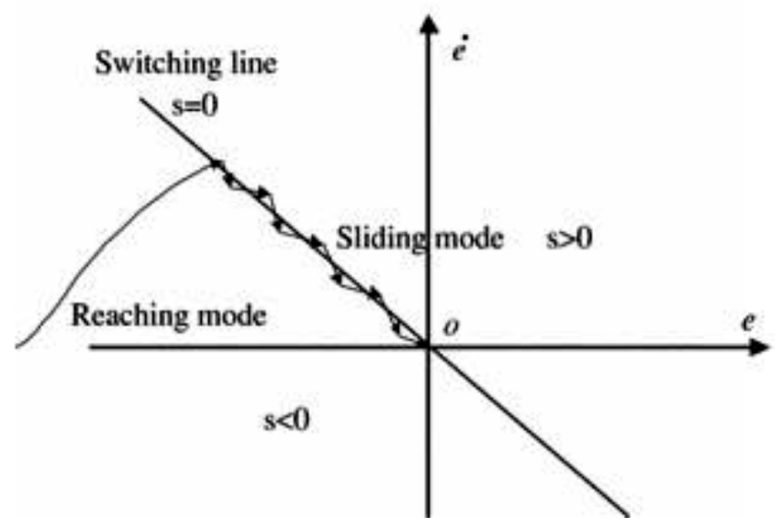

Figure 1. Phaseplane of tracking error

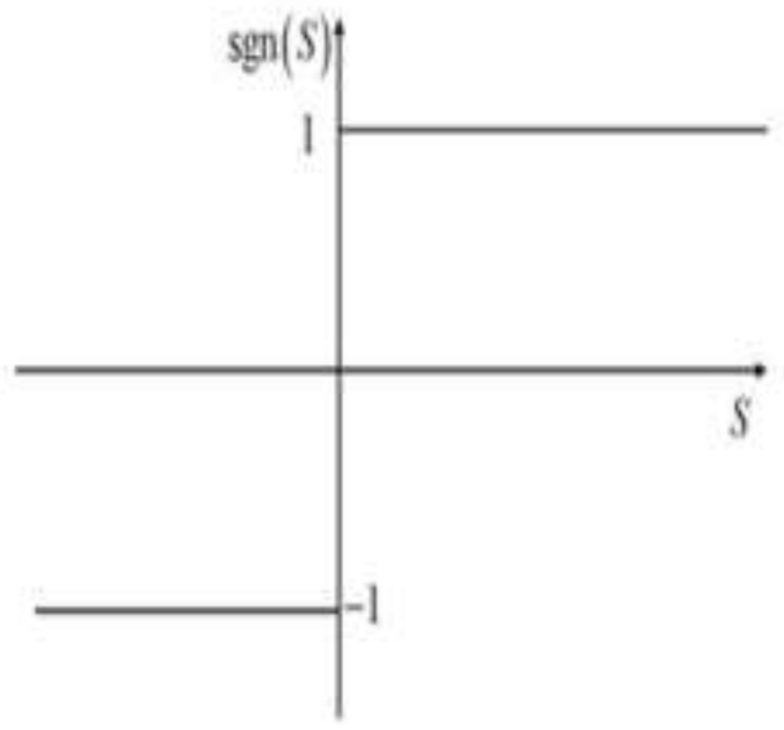

Figure 2. Signum and saturation function.

\section{Proposed Control Approach}

To consider the vigor of the unused control law, we accept that the moment framework (1) is subject to outside unsettling influences $\mathrm{d}$, and instabilities. In this case, the framework will be portrayed by:

$$
\ddot{x}=f_{0}(x, \dot{x})+\Delta f(x, \dot{x})+g_{0}(x, \dot{x}) u+\Delta g(x, \dot{x}) u+d,
$$

Where $\Delta \mathrm{f}(\mathrm{x}, \dot{\mathrm{x}})$ and $\Delta \mathrm{g}(\mathrm{x}, \dot{\mathrm{x}})$ represent bounded but unknown uncertainties. $\mathrm{f}_{0}(\mathrm{x}, \dot{\mathrm{x}})$ and $\mathrm{g}_{0}(\mathrm{x}, \dot{\mathrm{x}})$ represent denote respectively the nominal values of the function $\mathrm{f}(\mathrm{x}, \dot{\mathrm{x}})$ and $\mathrm{g}(\mathrm{x}, \dot{\mathrm{x}})$. Then, the proposed control law can be written as:

$$
u=g_{0}^{-1}\left(\ddot{x}_{r e f}-f_{0}-\lambda \dot{e}-\frac{s}{\rho^{2}}\right),
$$

To think about the steadiness and the strength of the closed-loop utilizing the control law (9), we ought to set up the unused expression of the sliding surface $s$. Based on the expression of the following mistake e, the time subordinate of $\mathrm{s}$ can be composed as:

$$
\begin{gathered}
\dot{s}=\lambda \dot{e}+\ddot{e} \\
\dot{s}=\lambda \dot{e}+\ddot{x}-\ddot{x}_{r e f}
\end{gathered}
$$

Using the definition of the control law, able to compose the expression of the moment time subsidiary of the reference signal as:

$$
\ddot{x}_{r e f}=f_{0}+g_{0} u+\lambda \dot{e}+\frac{s}{\rho^{2}},
$$

The unused portrayal of the framework demonstrates permits us to have:

$$
\ddot{x}=f_{0}(x, \dot{x})+\Delta f(x, \dot{x})+g_{0}(x, \dot{x}) u+\Delta g(x, \dot{x}) u+d
$$

Using conditions (11) and (12), the time subordinate of sliding surface, given by condition (10), can be communicated by:

$$
\begin{gathered}
\dot{s}=\lambda \dot{e}+f_{0}(x, \dot{x})+\Delta f(x, \dot{x})+g_{0}(x, \dot{x}) u \\
+\Delta g(x, \dot{x}) u+d-\left(f_{0}+g_{0} u+\lambda \dot{e}+\frac{S}{\rho^{2}}\right), \\
\dot{s}=\Delta f+\Delta g u+d-\frac{S}{\rho^{2}},
\end{gathered}
$$

Using the fact that both uncertainties and external disturbances are considered bounded, we consider an unused variable $\delta$ characterized by:

$$
\delta=\Delta f+\Delta g u+d,
$$

The speculation radiated remains sensible and reasonable since analyzing the condition (8), we note the physical limitations require that all terms of this condition to be bounded. Then, condition (13) can be modified as:

$$
\dot{s}=\delta-\frac{S}{\rho^{2}}
$$

Let's consider the taking after Lyapunov work: 


$$
V=\frac{1}{2} s^{2}
$$

Who's the time derivative can be expressed as:

$$
\dot{V}=s \dot{s}
$$

Using Equation (15), we obtain:

$$
\begin{gathered}
\dot{V}=s\left(\delta-\frac{S}{\rho^{2}}\right), \\
\dot{V}=s \delta-\frac{S^{2}}{\rho^{2}} \\
\dot{V}=-\frac{1}{2}\left((\rho \delta)^{2}-2 \frac{s}{2 \rho} \rho \delta+\frac{S^{2}}{\rho^{2}}\right)+\frac{(\rho \delta)^{2}}{2}-\frac{s^{2}}{2 \rho^{2}},
\end{gathered}
$$

This infers that:

$$
\dot{V} \leq \frac{(\rho \delta)^{2}}{2}-\frac{S^{2}}{2 \rho^{2}},
$$

Integrating the above inequality from $t=0$ to meeting time $t_{f}$ we get:

$$
\int_{0}^{t_{c}} s^{2} d t \leq 2 \rho^{2} V(0)+\rho^{4} \int_{0}^{t_{c}} \delta^{2} d t
$$

This imbalance ensures the meeting of the sliding surface to zero and after that the following blunder to zero. The plan strategy of the proposed control law is as follows:

Step 1: Calculate the nominal model of the system.

Step 2: Choose the sliding term $\lambda$

Step 3: Choose the term $\rho$

Figure 3 shows the graph of the proposed control law.

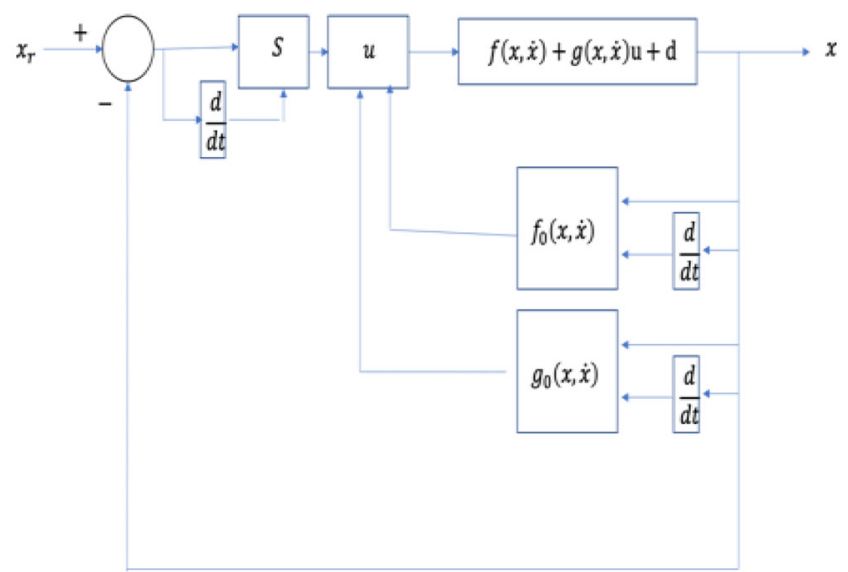

Figure 3. Design procedure of proposed control law.

\section{IDFIG Wind Turbine Application}

To expand our control methodology, we consider the DFIG wind turbine topology given by Figure 4 . So, we ought to create two controllers: The primary one is for the Rotor Side Converter (RSC) and the moment for Network Side Converter (GSC).

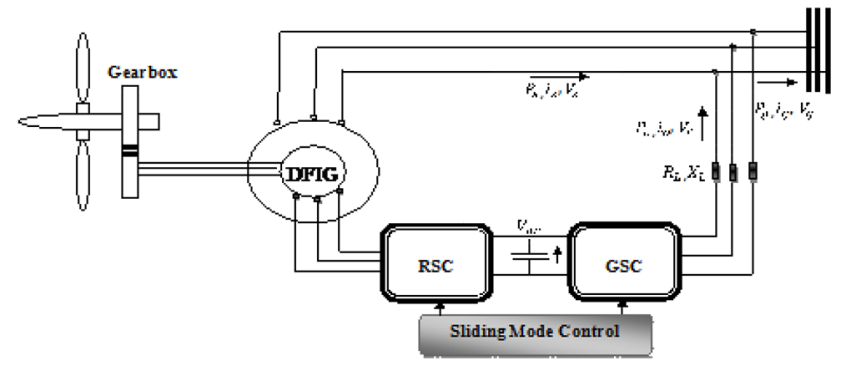

Figure 4. DFIG wind turbine topology.

\subsection{Rotor Side Converter Control}

Beneath the suspicion of direct attractive circuits and adjusted working conditions, the proportionate two stage demonstrate of the symmetrical DFIG, spoken to in dq reference outline is as takes after ${ }^{11}$ :

$$
\begin{aligned}
& V_{s d}=R_{s} i_{s d}+\frac{d \Phi_{s d}}{d t}-\emptyset_{s q} \omega_{s} \\
& V_{s q}=R_{s} i_{s q}+\frac{d \Phi_{s q}}{d t}+\emptyset_{s d} \omega_{s} \\
& V_{r d}=R_{r} i_{r d}+\frac{d \Phi_{r d}}{d t}-\emptyset_{r q} \omega_{r} \\
& V_{r q}=R_{s} i_{r q}+\frac{d \Phi_{r q}}{d t}+\emptyset_{r d} \omega_{r}
\end{aligned}
$$

The stator and rotor flux can be expressed as:

$$
\begin{aligned}
& \Phi_{s d}=L_{s} i_{s d}+M i_{r d} \\
& \Phi_{s q}=L_{s} i_{s q}+M i_{r q} \\
& \Phi_{r d}=L_{r} i_{r d}+M i_{s d} \\
& \Phi_{r q}=L_{r} i_{r q}+M i_{s q}
\end{aligned}
$$

By choosing a reference outline connected to the stator flux and the stator resistance is ignored, which could be a realist guess for medium and high power control machines utilized in wind energy change, the stator voltage vector is thus in quadrature development against stator flux and are given by ${ }^{12}$ :

$$
\left\{\begin{array}{c}
V_{s d}=0 \\
V_{s q}=\omega_{s} \Phi_{s d}
\end{array}\right.
$$




$$
\left\{\begin{array}{c}
\Phi_{s q}=0 \\
\Phi_{s d}=\Phi_{s}^{\prime}
\end{array}\right.
$$

After a few classical numerical controls, we can get:

$$
\begin{gathered}
V_{s d}=R_{s} a \Phi_{s d}-R_{s} c\left(\sigma L_{r} i_{r d}+\frac{M}{L_{s}} \frac{V_{s q}}{\omega_{s}}\right)+\frac{d V_{s q}}{d t}-\Phi_{s q} \omega_{s} \\
V_{s q}=R_{s} a \Phi_{s q}-R_{s} c\left(\sigma L_{r} i_{r q}+\frac{M}{L_{s}} \frac{V_{s d}}{\omega_{s}}\right)+\frac{d V_{s q}}{d t}+\Phi_{s d} \omega_{s} \\
V_{r d}=R_{r} b\left(\sigma L_{r} i_{r d}+\frac{M}{L_{s}} \frac{V_{s q}}{w_{s}}\right)+\sigma L_{r} \frac{d i_{r d}}{d t}-\omega_{r}\left(\sigma L_{r} i_{r q}+\frac{M}{L_{s}} \frac{V_{s d}}{\omega_{s}}\right) \\
V_{r} c \Phi_{s d}=R_{r} b\left(\sigma L_{r} i_{r q}+\frac{M}{L_{s}} \frac{V_{s d}}{w_{s}}\right)+\sigma L_{r} \frac{d i_{r q}}{d t}+\omega_{r}\left(\sigma L_{r} i_{r d}+\frac{M}{L_{s}} \frac{V_{s q}}{\omega_{s}}\right) \\
-R_{r} c \Phi_{s q}
\end{gathered}
$$

With: $\sigma=1-\frac{M^{2}}{L_{s} L_{r}} ; \quad a=\frac{1}{\sigma L_{s}} ; \quad b=\frac{1}{\sigma L_{r}} ; c=\frac{M}{\sigma L_{s} L_{r}}$ then we can write the state model as:

1)

$$
\dot{x}=f(X, t)+g(X, t) U_{d q},
$$

With:

$$
\begin{aligned}
& \dot{x}=\left[\begin{array}{c}
\frac{d \Phi_{s d}}{d t} \\
\frac{d \Phi_{s q}}{d t} \\
\frac{d i_{r d}}{d t} \\
\frac{d i_{r q}}{d t}
\end{array}\right] ; \quad U_{d q}=\left[\begin{array}{c}
V_{s d} \\
V_{s q} \\
V_{r d} \\
V_{r q}
\end{array}\right] \\
& g(X, t)=\left[\begin{array}{cccc}
1 & 0 & 0 & 0 \\
0 & 1 & 0 & 0 \\
0 & 0 & \frac{1}{\sigma L_{r}} & 0 \\
0 & 0 & 0 & \frac{1}{\sigma L_{r}}
\end{array}\right] \\
& \dot{x}=\left[\begin{array}{c}
\frac{d i_{s d}}{d t} \\
\frac{d i_{s q}}{d t} \\
\frac{d i_{r d}}{d t} \\
\frac{d i_{r q}}{d t}
\end{array}\right] ; \quad U_{d q}=\left[\begin{array}{c}
V_{s d} \\
V_{s q} \\
V_{r d} \\
V_{r q}
\end{array}\right] \\
& g(X, t)=\left[\begin{array}{cccc}
1 & 0 & 0 & 0 \\
0 & 1 & 0 & 0 \\
0 & 0 & \frac{1}{\sigma L_{r}} & 0 \\
0 & 0 & 0 & \frac{1}{\sigma L_{r}}
\end{array}\right] \\
& f(X, t)=\left[\begin{array}{c}
-R_{s} a \Phi_{s d}+R_{s} c\left(\sigma L_{r} i_{r d}+\frac{M}{L_{s}} \frac{V_{s q}}{\omega_{s}}\right)+\frac{d V_{s q}}{d t}+\Phi_{s q} \omega_{s} \\
-R_{s} a \Phi_{s q}-R_{s} c\left(\sigma L_{r} i_{r q}+\frac{M}{L_{s}} \frac{V_{s d}}{\omega_{s}}\right)+\frac{d V_{s q}}{d t}+\Phi_{s d} \omega_{s} \\
\frac{1}{\sigma L_{r}}\left(-R_{r} b\left(\sigma L_{r} i_{r d}+\frac{M}{L_{s}} \frac{V_{s q}}{w_{s}}\right)+R_{r} c \Phi_{s d}+\omega_{r}\left(\sigma L_{r} i_{r q}+\frac{M}{L_{s}} \frac{V_{s d}}{\omega_{s}}\right)\right) \\
\frac{1}{\sigma L_{r}}\left(-R_{r} b\left(\sigma L_{r} i_{r q}+\frac{M}{L_{s}} \frac{V_{s d}}{w_{s}}\right)+R_{r} c \Phi_{s q}-\omega_{r}\left(\sigma L_{r} i_{r d}+\frac{M}{L_{s}} \frac{V_{s q}}{\omega_{s}}\right)\right)
\end{array}\right]
\end{aligned}
$$

The stator dynamic and receptive control can be communicated as takes after:

$$
\left\{\begin{array}{c}
P_{s}=-\frac{3}{2} V_{s q} \frac{M}{L_{s}} i_{r q} \\
Q_{s}=\frac{3}{2}\left(\frac{V_{s q} \Phi_{s d}-V_{s q} M i_{r d}}{L_{s}}\right)
\end{array}\right.
$$

We comment that the rotor streams, which are connected to dynamic and responsive powers, have to be track fitting current references. Sliding surfaces speak to the blunder between the genuine and references rotor streams and are communicated as takes after ${ }^{13}$ :

$$
\left\{\begin{array}{l}
S_{d}=i_{r d \_r e f}-i_{r d} \\
S_{q}=i_{r q_{-} r e f}-i_{r q}
\end{array}\right.
$$

$\mathrm{V}_{\mathrm{rd}}$ and $\mathrm{V}_{\mathrm{rq}}$ will be the two components of the control vector utilized to imperative the framework to meet to S_d $=$ S_q $=0$. The proposed sliding mode control is:

$$
\left\{\begin{array}{l}
u_{d}=R_{r} b\left(\sigma L_{r} i_{r d}+\frac{M V_{s q}}{L_{s} \omega_{s}}\right)-R_{r} c \Phi_{s d}-\omega_{r}\left(\sigma L_{r} i_{r q}+\frac{M V_{s d}}{L_{s} \omega_{s}}\right)-\frac{S_{d}}{\rho_{d}^{2}} \\
u_{q}=R_{r} b\left(\sigma L_{r} i_{r q}+\frac{M V_{s d}}{L_{s} \omega_{s}}\right)-R_{r} c \Phi_{s q}-\omega_{r}\left(\sigma L_{r} i_{r d}+\frac{M V_{s q}}{L_{s} \omega_{s}}\right)-\frac{S_{q}}{\rho_{q}^{2}}
\end{array}\right.
$$

\subsection{Grid Side Converter Control}

The GSC is associated to the electrical lattice by a middle person line characterized by a resistance RL and a reactance XL. In a reference Stop outline related to the organize precise speed network equal to the synchronous speed, the electrical voltage condition is given by $\underline{14,15}$ :

$$
\left\{\begin{array}{c}
\frac{d i_{0 d}}{d t}=\frac{V_{0 d}}{L}-\frac{R}{L} i_{0 d}+\omega_{R} i_{0 q} \\
\frac{d i_{0 q}}{d t}=\frac{V_{0 q}}{L}-\frac{R}{L} i_{0 q}-\omega_{R} i_{0 d}-V_{g d}
\end{array},\right.
$$

The active and the reactive power are represented by follows:

$$
\left\{\begin{array}{l}
P_{0}=\frac{3}{2}\left(V_{g d} i_{0 d}+V_{g q} i_{0 q}\right) \\
Q_{0}=\frac{3}{2}\left(V_{g d} i_{0 d}-V_{g q} i_{0 q}\right)
\end{array}\right.
$$

Based on the orientation of grid voltage along Park d-axis, we can write:

$$
V_{g d}=\left|\bar{V}_{g}\right| \text { and } V_{g q}=0,
$$

Then, we can have:

$$
\left\{\begin{array}{c}
P_{0}=\frac{3}{2} V_{g d} i_{0 d} \\
Q_{0}=-\frac{3}{2} V_{g d} i_{0 q}
\end{array},\right.
$$


Hence the elements of the dynamic and responsive control are straightforwardly connected to the control of network streams $i_{\text {od }}$ and $i_{\text {oq }}$. Voltage is constant and equal to the nominal AC voltage. For the DFIG sliding mode controllers design, two exchanging surfaces are chosen as ${ }^{16}$ :

$$
\left\{\begin{array}{l}
S_{1}=i_{r d_{\_} r e f}-i_{r d} \\
S_{2}=i_{r q_{-} r e f}-i_{r q}
\end{array},\right.
$$

Where the reference values are given by:

$$
\begin{aligned}
& i_{0 d_{r e f}}=\frac{2 P_{0-r e f}}{3 V_{g d}} \\
& i_{0 q_{r e f}}=\frac{2 Q_{0-r e f}}{3 V_{g d}}
\end{aligned}
$$

As in the case of RSC control, we can write the control laws for GSC as:

$$
\left\{\begin{array}{l}
u_{d}=R_{L} i_{\text {odref }}-\omega_{R} L i_{\text {oqref }}-\frac{S_{1}}{\rho_{1}^{2}} \\
u_{q}=R_{L} i_{\text {oqref }}-\omega_{R} L i_{\text {odref }}-\frac{S_{2}}{\rho_{2}^{2}}
\end{array},\right.
$$

\section{Simulation and Results}

To test the execution of the proposed ERL based SMC in wind turbine active/reactive control; a comparative consider is conducted beneath variable wind speed scenarios. A 7.5 KW DFIG wind turbine, reenactment show is developed in MATLAB/Simulink. The parameters utilized are recorded in Table 1.

Figures 5 and 6 provide the reenactment comes about. We comment that the dynamic and receptive powers take after the required direction without chattering.

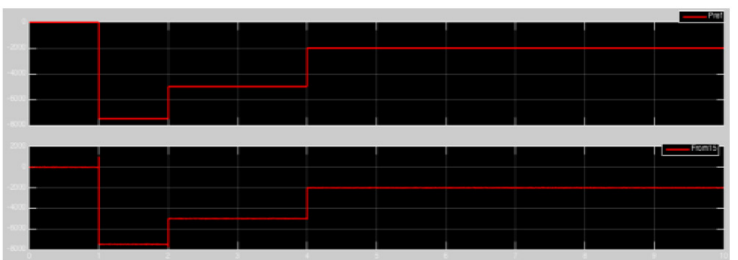

\begin{tabular}{|c|c|}
\hline Sample & Apoptotic cell population ${ }^{*}$ \\
\hline Voltage rated & $380 / 660$ \\
\hline Rated Power & $7.5 \mathrm{Kw}$ \\
\hline Stator resistor per phase & $R_{s}=0.455 \Omega$ \\
\hline Rotor resistor per phase & $R_{r}=0.62 \Omega$ \\
\hline $\begin{array}{l}\text { Inductance of the stator } \\
\text { winding }\end{array}$ & $L_{r}=0.081$ \\
\hline Stator frequency & $50 \mathrm{~Hz}$ \\
\hline Number of pole pairs & 2 \\
\hline Mutual inductance & $0.078 \mathrm{H}$ \\
\hline \multicolumn{2}{|c|}{ TURBINE parameters } \\
\hline Parameter & Value \\
\hline Diameter & $13 \mathrm{~m}$ \\
\hline Number of blades & 3 \\
\hline Gearbox & 35 \\
\hline \multicolumn{2}{|c|}{ (DFIG+TURBINE) parameters } \\
\hline Parameter & Value \\
\hline Coefficient of viscosity & $0.3125 \mathrm{Kg} \cdot \mathrm{m}^{2}$ \\
\hline Inertia of system & $0.00673 \mathrm{Kg} . \mathrm{m}^{2} / \mathrm{s}$ \\
\hline
\end{tabular}

Figure 5. Active power $\mathrm{P}$.

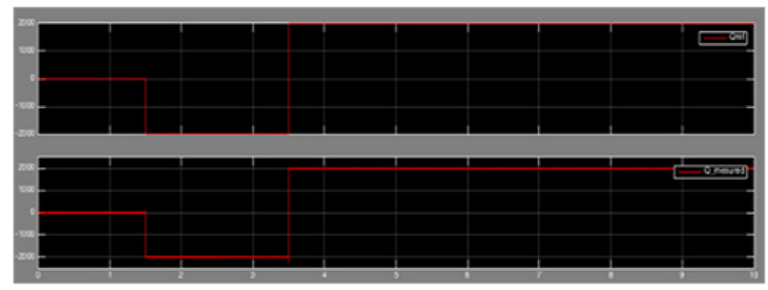

Figure 6. Reactive power Q.
Table 1. DFIG nominal

\section{Conclusion}

In this work, I have displayed a straightforward sliding mode controller for dynamic and receptive control for a wind turbine based on DFIG associated to the electrical framework. For this, utilized two rotor control converters connected by a DC voltage which permits the control vitality transitory between the network and the DFIG. So, two sliding mode controllers have been created both RSC and GSC. Reenactments come about appear that the control objective has been gotten and chattering marvel has been disposed of.

\section{Reference}

1. Eisenhut C, Krug F, Schram C, Klockl B. Wind-turbine model for system simulations near cut-in wind speed. IEEE Transactions on Energy Conversion. 2007; 22(2):414-20. https://doi.org/10.1109/TEC.2006.875473

2. Belmokhtar K, Doumbia ML, Agbossou K. Modelling and power control of wind turbine driving DFIG connected to the utility grid. Proceedings of the International Conference on Renewable Energies and Power Quality, ICREPQ; 2011. p. 1-6. https://doi.org/10.24084/ repqj09.490 
3. Tohidi A, Shamsaddinlou A, Sedigh AK. Multivariable input-output linearization sliding mode control of DFIG based wind energy conversion system. Asian Control Conference (ASCC); 2013. p. 1-6. https://doi.org/10.1109/ ASCC.2013.6606347

4. Mi M, Tapia G, Susperregui A, Camblong H. Sliding-mode control for DFIG rotor and grid-side converters under unbalanced and harmonically distorted grid voltage. IEEE Transactions on Energy Conversion. 2012; 27(2):328-39. https://doi.org/10.1109/TEC.2011.2181996

5. Bekakra Y, Attous DB. Active and reactive power control of a DFIG with MPPT for variable speed wind energy conversion using sliding mode control. World Journal of Engineering and Technology. 2011; 8:12-21.

6. Kairous D, Wamkeue R. DFIG-based fuzzy sliding-mode control of WECS with a fly wheel energy storage. Electric Power Systems Research. 2012; 93:16-23. https://doi. org/10.1016/j.epsr.2012.07.002

7. Bekakra Y, Attous DB. Sliding mode controls of active and reactive power of a DFIG with MPPT for variable speed wind energy conversion. Australian Journal of Basic and Applied Sciences. 2011; 5(12):2274-86.

8. Benbouzid M, Beltran B, Amirat Y, Yao G, Han J, Mangel H. Second-order sliding mode control for DFIG-based wind turbines fault ride-through capability enhancement. ISA Transactions. 2014; 53(3):827-33. PMid: 24530194. https://doi.org/10.1016/j.isatra.2014.01.006

9. Wen J, Zheng Y, Donghan F. A review on reliability assessment for wind power. Renewable and Sustainable Energy Reviews. 2009; 13(9):2485-94. https://doi. org/10.1016/j.rser.2009.06.006
10. Abid M, Mansouri A, Aissaoui A, Belabbes B. Sliding mode application in position control of an induction machine. Journal of Electrical Engineering. 2008; 59(6):322-7.

11. Power control of a wind energy conversion system based on a doubly fed induction generator using RST and sliding mode controllers. 2012. https://www.researchgate.net/ publication/269991427_Power_Control_of_a_Wind_Energy_ Conversion_System_based_on_a_Doubly_Fed_Induction_ Generator_using_RST_and_Sliding_Mode_Controllers

12. Wai RJ, Lin CM, Hsu CF. Adaptive fuzzy sliding-mode control for electrical servo drive. Fuzzy Sets and Systems. 2004; 143(2):295-310. https://doi.org/10.1016/S0165 0114(03)00199-4

13. Mansour M, Mansouri MN, Mmimouni MF. Study and control of a variable-speed wind-energy system connected to the grid. International Journal of Renewable Energy Research. 2011; 1(2):96-104.

14. Liao K, He Z, Xu Y, Chen G, Dong ZY, Wong KP. A sliding mode based damping control of DFIG for interarea power oscillations. IEEE Transactions on Sustainable Energy. 2017; 8(1):258-67. https://doi.org/10.1109/TSTE.2016.2597306

15. Martinez MI, Susperregui A, Tapia G, Xu L. Sliding-mode control of a wind turbine-driven double-fed induction generator under non-ideal grid voltages. IET Renewable Power Generation. 2013; 7(4):370-9. https://doi. org/10.1049/iet-rpg.2012.0172

16. Hamzaoui A, Essounbouli N, Zaytoon J. Fuzzy sliding mode control with a fuzzy switching function for non-linear uncertain multi-input multi-output systems. Proceedings of the Institution of Mechanical Engineers, Part I: Journal of Systems and Control Engineering. 2004; 218(4):287-97. https://doi.org/10.1177/095965180421800404 